\title{
TIPOS DE NOMES NA LÍNGUA XIKRÍN DO CATETÉ
}

\section{TYPE OF NOUNS IN XIKRÍN DO CATETÉ LANGUAGE}

Lucivaldo Silva da Costa Universidade Federal do Sul e Sudeste do Pará, UNIFESSPA, Marabá, PA, Brasil

\begin{abstract}
Resumo: Este artigo descreve os tipos de nomes existentes na língua Xikrín do Cateté. Com base em critérios estruturais, distribucionais e semânticos e, ainda tomando como parâmetro de análise, o critério de dependência, a língua Xikrín distingue três tipos de nomes, os nomes relativos, os nomes descritivos e os nomes absolutos.
\end{abstract}

Palavras-chave: Nomes; Lingua Xikrin; Dependência.

Abstract: This paper describes the types of nouns occurring in the Xikrín do Cateté language. Based on structural, distributional and semantics criteria, and, yet, taking into account dependence criterion, Xikrín language distinguishes between three types of nouns, that is to say, relative nouns, descriptive nouns and absolute nouns.

Keywords: Nouns; Xikrín Language; Dependence.

\section{Consideraçóes iniciais}

A língua Xikrín do Cateté ou mẽbêngôkre é uma variedade do Kayapó (RODRIGUES, 1986), falada pelo povo Xikrín, que vive na Terra Indígena com nome homônimo ao do povo, localizada no município de Parauapebas, sudeste do estado do Pará. Os Xikrín estão distribuídos atualmente em três aldeias: a aldeia Cateté, maior e mais antiga, tem aproximadamente 800 indivíduos; a aldeia Djudjêkô, com, aproximadamente, 250 indivíduos; e a aldeia Ô'ôdjám, a mais recente, com aproximadamente 150 habitantes.

\section{Nomes}

A língua Xikrín distingue três tipos de nomes, a saber: nomes relativos, nomes descritivos e nomes absolutos. Essas três distinçóes baseiam-se em critérios estruturais, distribucionais e semânticos, além do critério de dependência. 


\subsection{Nomes relativos}

Nomes relativos são assim definidos pela conjugação de dois critérios: o semântico e o morfossintático. Semanticamente, são nomes relativos todos aqueles cujos referentes têm existência relativa a algo ou a alguém. A natureza relativa desses nomes revela-se por meio de marcas morfossintáticas, através das quais são licenciados no discurso, numa relação de dependência com outro nominal, formando com este uma unidade sintática (CABRAL, 2001). Compóem essa classe nomes que referem entidades relacionadas à parte do corpo humano, a partes dos animais, a partes das plantas, a relaçóes de parentesco e a alguns termos referentes a utensílios e/ou adornos corporais, típicos da cultura material Xikrín, conforme ilustram os exemplos.

Partes do corpo humano

$\begin{array}{ll}\text { 01. tamakware } \quad \mathrm{j} \text {-ikra } \\ \text { Tamakwaré } & \mathrm{R}^{1} \text {-mão } \\ \text { 'mão de Tamakwaré' }\end{array}$

02. poi dz-wa

Poy $\quad \mathrm{R}^{1}$-dente

'dente de Poy'

03. i $\emptyset$-no

$1 \quad \mathrm{R}^{1}$-olho

'olho de mim' (meu olho)

Partes de animais e plantas

04. $\mathrm{m} \Lambda \mathrm{t}$ j-ara

arara $R^{1}$-pena

'pena de arara'

05. kwej $\emptyset$-пге

pássaro $\mathrm{R}^{1}$-ovo

'ovo de pássaro'

$\begin{array}{lll}\text { 06. } & \text { pi } & \emptyset \text {-k } \Lambda \\ \text { árvore } & \mathrm{R}^{1} \text {-casca }\end{array}$

'casca da árvore' 

07. pidzo
$\emptyset$-гã
fruto
$\mathrm{R}^{1}$-flor
'flor do fruto da árvore'(flor)

Relaçóes de parentesco
08. tute n-ĩjet
Tute $\mathrm{R}^{1}$-avô
'avô de Tute'
09. a ฤ-bãm
$2 \quad \mathrm{R}^{1}$-pai
'teu pai'
10. i dz-umreyet
$1 \quad \mathrm{R}^{1}$-sogro
'meu sogro'
12. bepnõrõti n-õbikwa
Bep Nhõrõ-Ti $\quad \mathrm{R}^{1}$-amigo
'amigo de Bep Nhõrõ-Ti'

Utensílios e adornos corporais

14. ikro n-ikrakamrıj

Ikro $\mathrm{R}^{1}$-anel

'anel de Ikrô'

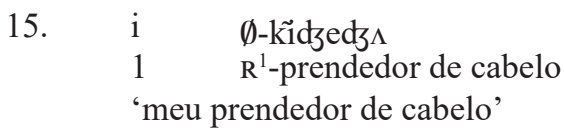

\subsection{Nomes descritivos}

Nomes descritivos são aqueles que, sob a perspectiva semântica, expressam noçóes que dizem respeito à qualidade, à sensaçáo física, a estado mental e à dinamicidade e, sob a perspectiva morfossintática, são sempre seguidos de seus determinantes, aos quais se ligam por meio de flexão relacional. Desempenham a função de modificadores e núcleo de predicados nominais, conforme mostram os exemplos a seguir. 


\section{Qualidade}

16. i

$$
1 \quad \mathrm{R}^{1} \text {-bom }
$$

'o bem de mim' (eu estou bem)

17. kri n-ipok

$$
\text { aldeia } \quad \mathrm{R}^{1} \text {-redondo }
$$

'o redondo do aldeia' (a aldeia é redonda)

$$
\begin{array}{llll}
\text { 18. } & \text { a } & \varnothing-k i ̃ & \text { j-abje } \\
2 & \text { R1-cabelo } & \text { R1-comprido } \\
& \text { 'o comprido do teu cabelo' (teu cabelo está comprido) }
\end{array}
$$

Sensaçöes físicas

$$
\begin{array}{lll}
\text { 19. } & \text { a } & \emptyset \text {-kayৎo } \\
2 & \mathrm{R}^{1} \text {-calor } \\
& \text { 'o teu calor' (você está com calor) }
\end{array}
$$

20. jo j-akri

água $\quad \mathrm{R}^{1}$-frio

'o frio da água' (a água está fria)

\section{Estados mentais}

21.

$$
\begin{aligned}
& \text { mẽnire } \quad \emptyset \text {-kaprĩre } \\
& \text { mulher } \quad \mathrm{R}^{1} \text {-tristeza } \\
& \text { 'a tristeza da mulher' (a mulher está triste) }
\end{aligned}
$$

22. benađ̧wәrə $\emptyset$-kĩj

chefe

$$
\mathrm{R}^{1} \text {-alegria }
$$

'a alegria do chefe' (o chefe está alegre)

\section{Dinamicidade}

$$
\begin{array}{llllll}
\text { 23. } & \text { ga } & \text { na } & \text { ga } & \text { a } & \emptyset \text {-prõt } \\
2 & \text { RLS } & 2 & 2 & \mathrm{R}^{1} \text {-corrida } \\
& \text { 'existiu tua corrida' (tu correste) }
\end{array}
$$

$\begin{array}{lllllll}24 & \text { ga } & \text { na } & \text { ga } & \text { arəp } & \text { a } & \emptyset \text {-kato } \\ & 2 & \text { RLS } & 2 & \text { já } & 2 & \text { R}^{1} \text {-saída } \\ & \text { 'já existiu tua saída' (tu saíste) }\end{array}$




\subsection{Nomes absolutos}

Os nomes absolutos constituem uma subclasse de temas nominais da língua Xikrín, cujos referentes não dependem de outra entidade para existir. Nomes desta subclasse são, sob o aspecto morfossintático, independentes e, sob o aspecto semântico, são referentes independentes, pois existem por si só. Estes temas designam entidades referentes à fauna, à flora, a elementos da natureza e a nomes de pessoas, como mostram os exemplos a seguir:

Nomes referentes à fauna

25. kukrit 'anta'

26. ajro 'porcão'

27. ropkrori 'onça pintada'

28. kaprãn 'jabuti'

29. kukej 'cotia'

30. kukoj 'macaco'

Nomes referentes à flora

31. pidzorã 'flor'

32. pi 'urucum'

33. aw 'mogno'

34. moj 'jatobá'

Nomes referentes a elementos da natureza

35. pika 'terra'

36. k^jkwa 'céu'

37. mitirwo 'lua'

38. mit 'sol'

39. kanetire 'estrela'

40. krãj 'serra'

Segundo Costa, os nomes referentes a manufaturas, a objetos da cultura material, nomes referenciais tomados de empréstimo da Língua Portuguesa, por força do contato com a sociedade circundante, e, ainda, nomes absolutos, quando ocorrem numa relação de dependência, são vinculados indiretamente a seus determinantes, mediados pelo nome -ó "pertence" (COSTA, 2002, p. 82; COSTA, 2015, p. 58), como mostram os exemplos seguintes: 
41

$\begin{array}{lll}i & n-\tilde{o} & k o \\ 1 & \mathrm{R}^{1} \text {-PERTENCE } & \text { borduna }\end{array}$

'meu pertence, a borduna'

42.

$\begin{array}{lll}a & n-\tilde{o} & k \wedge p \jmath \\ 2 & \mathrm{R}^{1} \text {-PERTENCE } & \text { remo } \\ \text { 'teu pertence, o remo' }\end{array}$

43. lusivawdo i $n-\tilde{o}$

profesor $\emptyset$-tũm

Lucivaldo $1 \quad \mathrm{R}^{1}$-PERTENCE professor $\mathrm{R}^{1}$-antigo

'Lucivaldo, meu professor antigo'

44. ba i $n$ - $\quad$ mãmãj

$1 \quad 1 \quad \mathrm{R}^{1}$-PERTENCE mamãe

'minha mamãe'

É interessante atentar para a estratégia de code switching feita pelo indígena nos exemplos 43 e 44, introduzindo em seus discursos os vocábulos 'mamãe' e 'professor'. Como tais vocábulos são empréstimos do Português, os falantes Xikrín as consideram como nomes absolutos.

\section{Consideraçóes finais}

Neste artigo buscamos mostrar, suscintamente, que, em Xikrín, os nomes são classificados em relativos, descritivos e absolutos, tendo como base, para tal classificação, critérios estruturais, distribucionais e semânticos, bem como o critério de dependência. Foi mostrado que os nomes relativos recebem flexão relacional para indicar contiguidade sintática com seus determinantes e diferenciam-se de nomes descritivos por serem constituídos por temas que referem entidades relacionadas a partes do corpo humano, a partes dos animais, a partes das plantas, a relaçôes de parentesco e a alguns termos referentes a utensílios e/ou adornos corporais, típicos da cultura material Xikrín, enquanto os nomes descritivos são formados por temas que expressam noçôes que dizem respeito à qualidade, à sensação física, a estado mental e à dinamicidade; núcleo de predicados nominais, conforme mostram os exemplos. Por fim, os nomes absolutos diferenciam-se dos dois primeiros por serem constituídos de temas cujos referentes não dependem de outra entidade para existir; existem por si só. Designam entidades referentes à fauna, à flora, a elementos da natureza e a nomes de pessoas. Assim, esperamos, com esse estudo, contribuir para o conhecimento da 
natureza dos nomes na língua Xikrín e para possíveis estudos comparativos com nomes de outras línguas da Família Jê.

\section{Referências}

ALVES, F. C. O timbira falado pelos Canela Apaniekrá: uma contribuição aos estudos da morfossintaxe de uma língua Jê. 2004. Tese (Doutorado em Linguística). Universidade Estadual de Campinas, Campinas, 2004.

CABRAL, A. S. A. C. Prefixos Relacionais na família Tupí-Guaraní. Boletim da ABRALIN. Fortaleza: Imprensa Universitária/UFC, n. 25, p. 213-226, 2001.

COSTA, L. S. Flexáo relacional, marcas pessoais e tipos de predicados em Xikrín: Contribuição para os estudos sobre ergatividade em línguas Jê. Dissertaçáo (Mestrado em Linguística). Universidade Federal do Pará, 2003.

COSTA, L. S. Prefixos relacionais no Xikrín. In: A. S. A. C. Cabral \& A. D. Rodrigues (Org.) Línguas indígenas brasileiras: fonologia, gramática e história. I Encontro Internacional do Grupo de Trabalho sobre Línguas Indígenas da ANPOLL. Anais. t. I, p. 81-85. Belém: EDUFPA, 2002.

. Uma descriçáo lexical da língua Xikrín do Cateté (Família Jê,

Tronco Macro-Jê). Tese (Doutorado em Linguística). Brasília: Universidade de Brasília-UnB, 2015.

DOURADO, L. Aspectos morfossintáticos da língua Panará. Tese (Doutorado em Linguística). Universidade Estadual de Campinas: Campinas, 2001.

FERREIRA, M. Estudo morfossintático da língua Parkatêjê. Tese (Doutorado em Linguística). Universidade Estadual de Campinas: Campinas, 2003a.

RODRIGUES, A. D. Línguas Brasileiras. Para o conhecimento das línguas Indígenas. São Paulo: Ediçôes Loyola, 1986. 